\title{
Nutritional Awareness and Status of Adolescent Girls Studying in Schools of Urban and Rural Areas of District Kurukshetra
}

\author{
Gurpreet Arora $^{1, *}$, G. K. Kochar ${ }^{2}$, Gunjan Soni ${ }^{3}$ \\ ${ }^{1}$ Dept. of Food \& Nutrition, College of Nursing, M. M. University, Mullana \\ ${ }^{2}$ Dept. of Food Technology, Amity University, Noida \\ ${ }^{3}$ Dept. of Home Science, Kurukshetra University, Kurukshetra \\ Email address: \\ Mail2gurpreetarora@gmail.com (G. Arora)
}

\section{To cite this article:}

Gurpreet Arora, G. K. Kochar, Gunjan Soni. Nutritional Awareness and Status of Adolescent Girls Studying in Schools of Urban and Rural Areas of District Kurukshetra. Journal of Food and Nutrition Sciences. Vol. 3, No. 3, 2015, pp. 126-130. doi: 10.11648/j.jfns.20150303.18

\begin{abstract}
Adolescent constitute about $20 \%$ of the total population, during this period they experiment for their adult identity and transition from dependence to independence. This leads to development of feeling of awkwardness and development of malnutrition among them. The malnutrition during this period affects their later life i.e., adulthood and old age. Keeping this in view, present study has been conducted on them with the objective to assess their level of nutritional awareness as well as eating habits and nutritional status. For the purpose of study, total 970 adolescent girls, 500 from urban and 470 from rural area were randomly selected from different Government schools situated in urban and rural areas of district Kurukshetra. Questionnaire cum interview schedule techniques were adopted for collecting the data related to family background and dietary pattern as well as of nutritional knowledge. Out of 970 female adolescent subjects, majority (65.46\%) of them were living in nuclear families followed by joint (34.53\%). The maximum subjects belonging to nuclear families were from urban area (71.2\%) as compared to rural area (59.36\%) but maximum number of joint families belonged to rural (40.63\%). About 89 $\%$ of adolescent girls were belonging to Hindu community. Sikh and Muslim girls constituted only $0.1 \%$ and $0.01 \%$ respectively. Regarding ordinal position maximum subjects of both urban and rural area had ordinal position first. The educational status of both mothers and fathers of the subjects were very low. Educated fathers of the respondents who were graduated were only $6.8 \%$ and mothers $1.2 \%$. fathers of most of the subjects were involved in agricultural activities( $58.64 \%$ ) and doing government jobs were only $0.84 \%$. mother of most of the respondents were housewife $85.89 \%$. maximum subjects of both rural and urban area were vegetarians and trend of taking lunch was very poor. Only $8.45 \%$ girls used to take the packed lunch. Pocket money used for eatable purposes at school was between the ranges of one to five rupees $68.15 \%$. 55\% girls purchased eatables sometimes and $24.2 \%$ never purchased any eatables. The money used to purchase and consume the eatables in the school was samosa and patties. Adolescent subjects belonging to urban area had better knowledge than subjects belonging to rural area. Regarding height and weight and body mass index, measurement of height and weight and calculation of BMI showed that about $81 \%$ were underweight and $1.8 \%$ was approaching towards obesity.
\end{abstract}

Keywords: Nutrition, Adolescent Girls, Malnutrition, Nutritional Awareness

\section{Introduction}

Adolescence, age between 10-19 years is the period of life when there is a rapid physical, social and psychological growth as well as sexual maturity. Adolescent girls are very important section of our society as they are the potential mothers and homemakers in future. Moreover, they perform various other roles in the family and the community. It is a transitional period of dramatic physical growth and development. This period is marked by rapid and sequential physical and mental changes that transform a small child into a young adult girl. During this stage, adolescent experiments for his adult identity and transition, from the total socioeconomic dependence to relative independence. They have to adjust with their physical growth, development and with their surroundings too. These unexpected changes may lead to feeling of awkwardness. In the case of adolescent girl, a large percentage, get married at below the age of 20 in India. 
It is regrettable that there is no period of adolescence in India as they budge from childhood to adulthood and soon become pregnant. These future impending mothers and home makers continue to face the restraints of nutritional scantiness.

Table 1. Family Profile of Urban and Rural Adolescent Subjects of District Kurukshetra

\begin{tabular}{|c|c|c|c|}
\hline Parameters & Rural (n-470) & Urban ( n-500) & $\begin{array}{l}\text { Grand Total } \\
(n-970)\end{array}$ \\
\hline \multicolumn{4}{|l|}{ Type Of Family } \\
\hline Nuclear & $279(59.36 \%)$ & $356(71.2 \%)$ & $635(65.46 \%)$ \\
\hline Joint & $191(40.63 \%)$ & $144(28.8 \%)$ & $335(34.53 \%)$ \\
\hline \multicolumn{4}{|l|}{ Religion } \\
\hline Hindu & $411(87.44 \%)$ & $452(90.4 \%)$ & $863(88.96 \%)$ \\
\hline Sikh & $52(11.06 \%)$ & $45(9 \%)$ & $97(0.1 \%)$ \\
\hline Muslim & $7(1.489 \%)$ & $03(0.6 \%)$ & $10(0.01 \%)$ \\
\hline Other & -- & -- & \\
\hline \multicolumn{4}{|c|}{ Ordinal Position Of Respondents In The Family } \\
\hline First & $217(46.17 \%)$ & $225(45 \%)$ & $442(45.56 \%)$ \\
\hline Middle & $142(30.213 \%)$ & $139(27.8 \%)$ & $281(28.96 \%)$ \\
\hline Last & $111(23.61 \%)$ & $136(27 \%)$ & $247(25.46 \%)$ \\
\hline \multicolumn{4}{|c|}{ Hereditary Problems In The Family } \\
\hline Diabetes & $62(36.9 \%)$ & $75(15 \%)$ & $137(33.66 \%)$ \\
\hline High Bp & $53(31.54 \%)$ & $72(14.4 \%)$ & $125(30.71 \%)$ \\
\hline Low Bp & $12(7.143 \%)$ & $17(3.4 \%)$ & $29(7.125 \%)$ \\
\hline Obesity & $31(18.452 \%)$ & $56(11.2 \%)$ & $87(21.37 \%)$ \\
\hline Other & $10(5.952 \%)$ & $19(3.8 \%)$ & $29(7.125 \%)$ \\
\hline \multicolumn{4}{|c|}{ Educational And Occupational Status Of Parents } \\
\hline \multicolumn{4}{|c|}{ Education Of Father } \\
\hline Uneducated & $69(14.9 \%)$ & $86(17.47 \%)$ & $156(16.33 \%)$ \\
\hline Primary & $168(36.28 \%)$ & $268(54.47 \%)$ & $435(45.5 \%)$ \\
\hline Secondary & $177(38.2 \%)$ & $122(24.8 \%)$ & $299(31.3 \%)$ \\
\hline Graduate & $39(8.42 \%)$ & $12(2.43 \%)$ & $51(5.34 \%)$ \\
\hline $\begin{array}{l}\text { Post } \\
\text { Graduate/Above }\end{array}$ & $10(2.15 \%)$ & $04(0.81 \%)$ & $14(1.46 \%)$ \\
\hline \multicolumn{4}{|c|}{ Education Of Mother } \\
\hline Uneducated & $219(46.79 \%)$ & $190(38.3 \%)$ & $409(42.42 \%)$ \\
\hline Primary & $189(40.38 \%)$ & $202(40.7 \%)$ & $392(40.66 \%)$ \\
\hline Secondary & $60(12.82 \%)$ & $92(18.54 \%)$ & $151(15.66 \%)$ \\
\hline Graduate & -- & $12(2.42 \%)$ & $12(1.244 \%)$ \\
\hline $\begin{array}{l}\text { Post } \\
\text { Graduate/Above }\end{array}$ & -- & -- & -- \\
\hline \multicolumn{4}{|c|}{ Occupation Of Father } \\
\hline Unemployed & $27(5.83 \%)$ & $31(6.3 \%)$ & $59(6.18 \%)$ \\
\hline Private Job & $57(12.31 \%)$ & $55(11.17 \%)$ & $111(11.62 \%)$ \\
\hline $\begin{array}{l}\text { Government } \\
\text { Job }\end{array}$ & -- & $8(1.62 \%)$ & $8(0.84 \%)$ \\
\hline Labourer & $268(57.88 \%)$ & $292(59.34 \%)$ & $560(58.64 \%)$ \\
\hline $\begin{array}{l}\text { Self Employed/ } \\
\text { Business }\end{array}$ & $111(23.97 \%)$ & $106(21.54 \%)$ & $217(22.72 \%)$ \\
\hline \multicolumn{4}{|c|}{ Occupation Of Mother } \\
\hline Housewife & $411(87.82 \%)$ & $416(83.87 \%)$ & $828(85.89 \%)$ \\
\hline Private Job & -- & $16(3.23 \%)$ & $16(1.66 \%)$ \\
\hline $\begin{array}{l}\text { Government } \\
\text { Job }\end{array}$ & -- & -- & \\
\hline Labourer & $48(10.25 \%)$ & $24(4.84 \%)$ & $71(7.36 \%)$ \\
\hline $\begin{array}{l}\text { Self Employed/ } \\
\text { Business }\end{array}$ & $09(1.92 \%)$ & $12(2.42 \%)$ & $21(2.18 \%)$ \\
\hline Other & -- & $28(5.64 \%)$ & $28(2.9 \%)$ \\
\hline
\end{tabular}

In most developing countries, nutrition initiatives have been focusing "on children and women, thus neglecting adolescents. Addressing the nutritional needs of adolescents could be an important step towards breaking the vicious cycle of intergenerational malnutrition, chronic diseases, and poverty. Epidemiological evidence from both the developed and developing countries indicates that there is a link between fetal under nutrition and increased risk of various chronic during adulthood (Adolescent Nutrition, WHO, 2006).

Adolescents are tomorrow's adult population and their health and well being are crucial. Yet, interest in the health of adolescents is relatively recent and a focus on nutrition is even more recent with the exception of adolescent pregnancy. The future economic development of poorer countries rests in large part on the prospects of having increasing proportion of future adults who are educated, healthy, and economically productive (Discussion Papers, WHO, 2005)

The main nutritional deficiency in female adolescent is iron deficiency anemia. A very few literature is available on adolescent's knowledge about nutrition, practices and attitude towards healthy eating habits and nutritional status. Therefore the present study has been undertaken with the following objective: To assess and evaluate awareness about nutrition, eating behavior and nutritional status of adolescent girls.

Materials and methods: Adolescent girls (970) between 13-18 years of age, were chosen from urban (500) and rural (470) areas of district Kurukshetra. Questionnaire cum interview method was adopted for collecting the data regarding family background and dietary pattern as well as of nutritional awareness. Anthropometric measurements like height and weight and body mass index were used in the assessment of nutritional status of the adolescent subjects

Family profile: questions related to family profile included type of family, caste, religion, ordinal position of each girl, hereditary problems and family composition of the subjects.

Personal profile: under this, information regarding school in which subjects were studying and educational status of the respondents were gathered.

Anthropometric measurements: it is a technique of quantitatively expressing the form of body; Anthropometric measurements vary in number and complexity, but can help in detecting sub-clinical stages of malnutrition. It has been recognized as a reliable tool in identification of nutritionally vulnerable groups.

Considering this, the height and weight were measured to assess the growth and nutritional status of the adolescent girls. Height was measured by using the methods of (Jelliffe, 1966). The weight was recorded in kilograms, to the nearest (Jelliffe, 1966 and ICMR, 2005).Comparison of anthropometric measurements with ICMR, NCHS and other reference values helped to determine growth performance, prevalence and incidence of degree of malnutrition among the adolescent females. The teenagers were classified according to their BMI as per classification given by James et. al., (1988). 


\section{Result \& Discussion}

\section{Family Profile of the Respondents}

Type of Family: Majority (65.46\%) of female adolescent subjects were belonging to nuclear families followed by joint $(34.53 \%)$. The maximum subjects belonging to nuclear families were from urban area (71.2\%) as compared to rural area $(59.36 \%)$ but maximum number of joint families belonged to rural $(40.63 \%)$.(Table 1$)$

Religion: The maximum subjects $(88.96 \%)$ were belonging to Hindu community. Sikh and Muslim girls constituted only $0.1 \%$ and $0.01 \%$ respectively.(Table: 1$)$

Ordinal Position Of Respondents: (45.56\%) were the first child of their families followed by middle child $(28.96 \%)$ and $(25.46 \%)$ last child of their families. The maximum number of subjects was the first child in both urban (45\%) and rural (46.17\%) group. (Table:1)

\section{Educational and Occupational Status of Parents}

Educational Status of Fathers: Educational status is an important indicator to judge the socio economic status as well as nutritional status of that community. Among all the selected subjects, $45.5 \%$ of the fathers were primary educated, $31.3 \%$ were secondary educated, $16.33 \%$ were uneducated and the remaining $(6.8 \%)$ were graduates or post graduates and above.

Amid uneducated fathers, $44.23 \%$ were from rural area and $55.12 \%$ were from urban area which means urban areas have a large proportion of uneducated fathers.

In rural area, maximum proportion of the fathers $(38.2 \%)$ were secondary educated whereas in urban area, maximum proportion of the fathers $(54.47 \%)$ were primary educated.

It has been observed that the percentage of fathers who were graduate or post graduate and above was very less contributing $10.57 \%$ in rural areas and $3.24 \%$ in urban areas.

Educational Status Of Mothers: Majority (42.42\%) of mothers of the respondents were uneducated, $40.66 \%$ of the mothers were primary educated, $15.66 \%$ were secondary educated, and the remaining $(1.244 \%)$ were graduates. Among uneducated mothers, $53.5 \%$ were from rural area and $46.45 \%$ were from urban area which means rural areas have a large proportion of uneducated mothers.

In rural area, maximum proportion of the mothers $(46.79 \%)$ were uneducated whereas in urban area, maximum proportion of the mothers $(40.7 \%)$ were primary educated.

It has been observed that the percentage of mothers who were graduate was very less.

Occupational Status Of Fathers: Fathers of $58.64 \%$, $22.72 \%, 11.62 \%$ and $0.84 \%$ were involved in agricultural activities (as labourers), in their own business, private jobs and government jobs respectively. $6.18 \%$ of the total was unemployed. In rural area, none of the father was employed in government job whereas in urban area, this figure was $1.62 \%$.
In rural and urban areas, maximum proportion of fathers was employed as labourer and figure was $51.88 \%$ and $59.39 \%$ respectively.

Occupational Status of Mothers: Among all the selected subjects, $85.89 \%, 7.36 \%, 2.18 \%, 1.66 \%$ and $2.9 \%$ of the mothers were housewives, labourers, involved in their business, doing private jobs and involved in other jobs respectively.

Table 2. Dietary Patterns of the Adolescent Subjects of Rural and Urban Area of District Kurukshetra

\begin{tabular}{|c|c|c|c|}
\hline Parameter & Rural (n-470) & $\begin{array}{l}\text { Urban (n- } \\
500)\end{array}$ & Grand Total ( n- 970) \\
\hline \multicolumn{4}{|c|}{ Dietary Habits } \\
\hline Veg & $213(45.31 \%)$ & $172(34.4 \%)$ & $385(39.69 \%)$ \\
\hline Non-Veg & $109(23.191 \%)$ & $133(26.6 \%)$ & $242(24.94 \%)$ \\
\hline Ovatarian & $158(33.6 \%)$ & $195(39 \%)$ & $353(36.39 \%)$ \\
\hline \multicolumn{4}{|c|}{ Do You Take Packed Lunch To School? } \\
\hline Yes & $55(11.7 \%)$ & $27(5.4 \%)$ & $82(8.45 \%)$ \\
\hline No & $388(82.55 \%)$ & $459(91.8 \%)$ & $847(87.31 \%)$ \\
\hline Sometimes & $27(5.744 \%)$ & $14(2.8 \%)$ & $41(4.22 \%)$ \\
\hline \multicolumn{4}{|c|}{ Details Of Pocket Money Taken From Parents } \\
\hline Amount & Rural & Urban & \\
\hline Nil & $94(20 \%)$ & $76(15.2 \%)$ & $170(17.5 \%)$ \\
\hline $1-5$ & $284(60.84 \%)$ & $196(39.2 \%)$ & $480(49.48 \%)$ \\
\hline $6-10$ & $82(17.44 \%)$ & $188(37.6 \%)$ & $270(27.83 \%)$ \\
\hline $11-15$ & -- & $12(2.4 \%)$ & $12(1.23 \%)$ \\
\hline $16-20$ & $10(2.12 \%)$ & $24(4.8 \%)$ & $34(3.5 \%)$ \\
\hline $21-25$ & -- & $4(0.8 \%)$ & $4(0.41 \%)$ \\
\hline \multicolumn{4}{|c|}{ Amount Spent On Eatables From Pocket Money } \\
\hline Amount & Rural & Urban & \\
\hline Nil & $160(34.04 \%)$ & $76(15.2 \%)$ & $236(24.32 \%)$ \\
\hline $1-5$ & $256(54.46 \%)$ & $344(68.8 \%)$ & $600(61.85 \%)$ \\
\hline $6-10$ & $47(10 \%)$ & $72(14.4 \%)$ & $119(12.26 \%)$ \\
\hline $11-15$ & $5(1.06 \%)$ & $4(0.8 \%)$ & $9(0.92 \%)$ \\
\hline $16-20$ & $2(0.425 \%)$ & $0(0 \%)$ & $2(0.20 \%)$ \\
\hline $21-25$ & -- & $4(0.8 \%)$ & $4(0.41 \%)$ \\
\hline \multicolumn{4}{|c|}{ Frequency Of Purchasing Eatable Items } \\
\hline Sometimes & $227(48.2 \%)$ & $309(61.8 \%)$ & $536(55.25 \%)$ \\
\hline Weekly & $6(1.27 \%)$ & $8(1.6 \%)$ & $14(1.4 \%)$ \\
\hline Daily & $77(16.3 \%)$ & $107(21.4 \%)$ & $184(18.96 \%)$ \\
\hline Never & $160(34.04 \%)$ & $76(15.2 \%)$ & $236(24.32 \%)$ \\
\hline \multicolumn{4}{|c|}{$\begin{array}{l}\text { Name Of Snacks Frequently Purchased By } \\
\text { Adolescent Girls }\end{array}$} \\
\hline $\begin{array}{l}\text { Samosa/ } \\
\text { Patties } \\
\text { Funflips/ }\end{array}$ & $201(64.83 \%)$ & $204(48.11 \%)$ & $405(41.75 \%)$ \\
\hline $\begin{array}{l}\text { Kurkure/ } \\
\text { Chips }\end{array}$ & $47(15.16 \%)$ & $108(25.471 \%)$ & $155(15.97 \%)$ \\
\hline $\begin{array}{l}\text { Chocolate/ } \\
\text { Toffee }\end{array}$ & $40(12.9 \%)$ & $92(21.69 \%)$ & $132(13.60 \%)$ \\
\hline Bisicuit & $10(3.225 \%)$ & $8(1.88 \%)$ & $18(1.85 \%)$ \\
\hline Fruits & $5(1.61 \%)$ & $4(0.94 \%)$ & $9(0.92 \%)$ \\
\hline Others & $7(2.258 \%)$ & $8(1.88 \%)$ & $15(1.54 \%)$ \\
\hline
\end{tabular}


In rural areas, a large proportion of the mothers were housewives contributing $87.82 \%$. None of the mother was engaged in private/ government jobs unlike urban areas where this figure was $3.23 \%$. In rural areas, $10.25 \%$ of the mothers were labourers whereas this figure is quite less (4.84.5) when urban areas were seen. (Table: 1)

Dietary Habits - Data regarding the dietary habits of selected adolescent girls clarify that maximum girls from both urban and rural group were consuming vegetarian diet regularly in their meals even if they were non-vegetarian. Among all them maximum subjects (39.69\%) were observed vegetarians followed by ovaterians $(36.39 \%)$ and only $24.94 \%$ of the subjects were found non vegetarians. This occasional consumption of non vegetarian meals by the girls might be due to their weak socio economic status.

Nearly $23.19 \%$ of the girls were non vegetarian in rural group and $26.6 \%$ in urban group however most of them consumed these products occasionally or once in a while.

Maximum subjects in rural area $(45.31 \%)$ were having vegetarian food habits as compared to urban (34.4\%). In urban area group maximum subjects were ovatarains (39\%). (Table: 2)

Packed Lunch - The trend of packed lunch was not common in the subjects of both groups. Among all the (970) subjects only $8.45 \%$ girls used to take lunch with them. Maximum subjects in rural areas $(20 \%)$ were taking packed lunch as compared to urban (15\%) however the percentages of both groups are considered low. The reason behind this might be the provision of canteens in schools and outside schools. Other main reason of not taking lunch dislikes of given packed meals. (Table: 2)

Details Of Pocket Money - data regarding the amount of pocket money taken by the adolescent girls belonging to rural and urban area. Among the (970)selected girls the maximum amount $(68.15 \%)$ received from parents is between the ranges of one to five rupees. The minimum percentage was $0.20 \%$ amount ranging $21-25$ rupees. The number of rural girls $(34.4 \%)$ who did not take money from parents are comparatively higher than urban group girls(15.2\%). (Table: 2 )

Frequency of Purchasing Eatable Items: $55 \%$ girls out of total (970) selected girls purchased eatables sometimes and $24.2 \%$ never purchased any eatables. The maximum amount spent on eatable items belonged to urban group $61.8 \% \quad 1.6 \% \quad \& \quad 21.4 \%$ sometimes, weekely and daily respectively and amount spent on eatables from rural group were $48.2 \% 1.27 \%$ \& $16.3 \%$ sometimes, weekely and daily respectively. (Table: 2 )

Name Of Preferred Snacks Frequently Purchased By Adolescent Girls: samosa and patties were the only snacks most liked and purchased by the both urban(34.11\%) and rural $(64.83 \%)$ adolescent girls. The most disliked and less purchased snacks were fruits in both urban (1.61\%) and rural $(0.94 \%)$ groups. (Table: 2$)$
Table 3. Level of Nutritional Awareness in Experimental Adolescent Girls of Urban and Rural Areas

\begin{tabular}{llll}
\hline Parameter & Rural (n-470) & Urban (n-500) & $\begin{array}{l}\text { Grand Total } \\
\text { (n-970) }\end{array}$ \\
\hline \multicolumn{2}{l}{ Nutritional Knowledge } & & \\
Nil & $170(36.17 \%)$ & $121(24.2 \%)$ & $291(30 \%)$ \\
Marginal & $147(31.27 \%)$ & $152(30.4 \%)$ & $299(30.82 \%)$ \\
Average & $99(21.06 \%)$ & $124(24.8 \%)$ & $223(22.98 \%)$ \\
Good & $35(7.446 \%)$ & $71(14.2 \%)$ & $106(10.92 \%)$ \\
Very Good & $19(4.042 \%)$ & $32(6.4 \%)$ & $51(5.25 \%)$ \\
\hline
\end{tabular}

Awareness about Nutrition

Nutritional knowledge: females of urban group were having better nutritional knowledge than the girls of rural group, the nutritional awareness was found comparatively better in the subjects belonging to urban group. In rural group girls did not show any awareness about nutritional knowledge, $31.27 \%$ of them knew marginally and $21.06 \%$ were having average knowledge of nutrition whereas only $4.04 \%$ were having good nutritional knowledge about nutrition. In urban and rural adolescent girls 36.17 and $34.2 \%$ did not possess any nutritional knowledge, whereas rests of them were having marginal to average knowledge about nutrition.

Table 4. Anthropometric Measurements

\begin{tabular}{llll}
\hline Parameter & Rural (n-470) & $\begin{array}{l}\text { Urban }(\mathbf{n}- \\
\mathbf{5 0 0})\end{array}$ & $\begin{array}{l}\text { Grand Total (n- } \\
\mathbf{9 7 0})\end{array}$ \\
\hline $\begin{array}{l}\text { Weight }(\mathrm{kg}) \\
20-25\end{array}$ & - & $28(5.6 \%)$ & $28(2.88 \%)$ \\
$26-30$ & $94(20 \%)$ & $108(21.6 \%)$ & $202(20.82 \%)$ \\
$31-35$ & $150(31.91 \%)$ & $112(22.4 \%)$ & $262(27.01 \%)$ \\
$36-40$ & $160(34.04 \%)$ & $172(34.4 \%)$ & $332(34.22 \%)$ \\
$41-45$ & $28(5.9 \%)$ & $48(9.6 \%)$ & $76(7.83 \%)$ \\
$46-50$ & $28(5.9 \%)$ & $24(4.8 \%)$ & $52(5.36 \%)$ \\
$51-55$ & $10(2.12 \%)$ & $08(1.6 \%)$ & $18(1.85 \%)$ \\
Height(cm) & & & \\
$121-130$ & -- & $12(2.4 \%)$ & $12(1.2 \%)$ \\
$131-140$ & $66(14.04 \%)$ & $52(10.4 \%)$ & $118(12.16 \%)$ \\
$141-150$ & $197(41.91 \%)$ & $168(33.6 \%)$ & $365(37.6 \%)$ \\
$151-160$ & $207(44.04 \%)$ & $224(44.8 \%)$ & $431(44.4 \%)$ \\
$161-170$ & -- & $44(8.8 \%)$ & $44(4.53 \%)$ \\
BMI(kg/m2) & & & \\
$<18.5$ & $374(79.5 \%)$ & $412(82.4 \%)$ & $786(81.03 \%)$ \\
$18.5-24.9$ & $94(20 \%)$ & $72(14.4 \%)$ & $166(17.11 \%)$ \\
$25-29.9$ & $02(0.4 \%)$ & $16(3.2 \%)$ & $18(1.85 \%)$ \\
$>30$ & -- & -- & -- \\
\hline
\end{tabular}

Body Mass Index: Out of total 970 females, $81 \%$ females were found underweight and only $1.85 \%$ were found at high risk over weight. Only $17.11 \%$ girls out of total girls were having normal BMI. (Table:4)

\section{Conclusion}

The low values for anthropometry and socio-economic stage acquired from this study suggest that there is need for improvement in the nutritional status of these adolescents. Also, more attention needs to be done to address the issue of adolescent malnutrition. Various macro and micro- nutrient 
deficiencies are more common nutritional problems in kurukshetra. This may arise different types of complications that may be life threaten for adolescent girls. There is no magic pill that can reduce or increase the nutritional status of the girls. If the individuals are cognizant about nutritional knowledge, nutritional deficiency diseases, nutritional value of food and dietary practices, they can easily beat those problems and can make their body sound and healthy without assassinating excess money.

\section{References}

[1] Croll, J. K., Neumark-Sztainer, D. and story M.(2001) healthy eating: what does it means to adolescents. J. Nutritional Edu. 33: 193-198.

[2] Dalsky, R. (2006) Food and the adolescent females. Available at www.afpafitness.com.

[3] Horwath, C.C.(1991) Dietary intake and nutritional status among university undergraduates. Nutr. Res. 11 : 395-404.
[4] ICMR (1992) Nutrient requirements and recommended dietary allowances for Indians. Indian Council Of Medical Research, New Delhi.

[5] James, W.P.T., Ferro-Liuzzi and Waterlow, J.C (1988) Definition of chronic energy deficiency in adults- report of working party of the intervention dietary energy consultation group. Am.J.Clin. Nutr. 42: 969-981.

[6] WHO. Adolescent Nutrition: A review of the Situation in Selected South East-Asian Countries.2006

[7] WHO. Discussion Papers on Adolescents' Nutrition in Adolescence- Issues and Challenges for Health Sector. 2005

[8] WHO. Healthy Nutrition an Essential Element of a HealthPromoting School Global School Health Initiative- Division of Health Promotion, Education and Communication. 1998

[9] Jelliffe, O.B. (1996) The Assessment Of Nutritional Status Of The Community Monograph Series no.53. World Health Organization, Geneva. 